\title{
LITOGEOQUÍMICA E PETROGRAFIA APLICADAS AO ESTUDO DE PROVENIÊNCIA NA SESSÃO APTIANA AFLORANTE NA PORÇÃO NORTE DA SUB-BACIA DE ALAGOAS, NE BRASIL.
}

\section{LITOGEOCHEMISTRY AND PETROGRAPHY APPLIED TO PROVENANCE STUDY IN THE EMERGED PORTION OF THE APTIAN SEDIMENTATION OF ALAGOAS BASIN, NE BRAZIL.}

\author{
Gabriela Menezes ALMEIDA ${ }^{1}$, Maria de Lourdes da Silva ROSA ${ }^{1,2}$, Maria Rosilene \\ Ferreira de MENEZES ${ }^{3}$ \\ (1) Pós-Graduação em Geociências e Análise de Bacias, Universidade Federal de Sergipe. Email: geol.gmalmeida@gmail.com \\ (2) Laboratório de Petrologia Aplicado à Pesquisa Mineral, Universidade Federal de Sergipe, Cidade Universitária Prof. José Aloísio \\ de Campos, São Cristóvão, SE, Brasil. Email: lrosa@ufs.br \\ (3) Petrobras, Petróleo Brasileiro S.A., Unidade de Operações de Sergipe e Alagoas, Aracaju, SE, Brasil. \\ Email: rosimenezes@petrobras.com.br
}

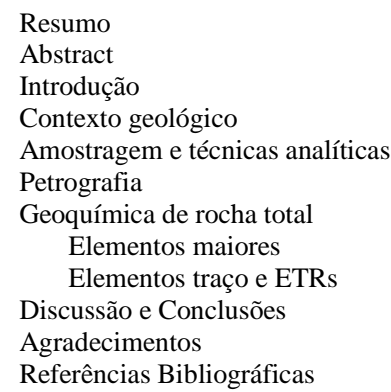

\begin{abstract}
RESUMO - Os afloramentos Praia de Japaratinga, Barreiras do Boqueirão e Morro de Camaragibe, sub-bacia de Alagoas, estão localizados nos municípios de Japaratinga e Passo de Camaragibe, ao norte do Estado de Alagoas. Essas exposições exibem fácies de depósitos de um sistema flúvio-deltaico-turbidítico, até então atribuídos à Formação Maceió, de idade eoptiana, depositada no fim do estágio rifte da bacia. As fácies desses afloramentos compõem depósitos de fluxos gravitacionais catastróficos com duas direções principais de paleocorrentes: uma dominantemente SW, a qual tem seus estratos parcialmente erodidos por fluxos canalizados com paleocorrente de direção SE. Este trabalho buscou fazer uma análise geoquímica de amostras dos três afloramentos de modo a auxiliar no estudo de proveniência desses sedimentos. Para tal utilizou-se dados de geoquímica de rocha total com análise de elementos maiores, traço e ETRs. Os resultados mostram a existência de ao menos a duas áreas fontes distintas de acordo com a assinatura geoquímica e conforme a direção de paleocorrente das amostras analisadas.
\end{abstract}

Palavras-chave: proveniência, Bacia de Sergipe-Alagoas, fase rifte.

\begin{abstract}
The Praia de Japaratinga, Barreiras do Boqueirão and Morro de Camaragibe outcrops, Alagoas Basin, are located in the cities of Japaratinga and Passo de Camaragibe, northern Alagoas State. These exposures show facies of a fluvio-deltaic-turbitidy system deposit, until now assigned to Maceió Formation, Eoptian age, deposited in the end of the rift phase. The outcrops facies compose deposits of catastrophic gravitational flows with two main paleocurrent directions: one SW dominant, which has its strata partially eroded by channeled flows with SE paleocurrent. This paper aims a geochemical analysis in samples of the three outcrops to help in the provenance study of these sediments through geochemical role-rock composition and analysis of major, minor and rareearth elements. The results show the existence of at least two distinct source areas due to the difference in the geochemical signatures and according to the paleocurrent direction of the samples analyzed.
\end{abstract}

Keywords: provenance, Sergipe-Alagoas Basin, rift phase.

\section{INTRODUÇÃO}

O estudo de proveniência é uma importante ferramenta para a compreensão da origem e evolução das bacias sedimentares. Métodos distintos podem ser aplicados para tal finalidade tais como a ambiência tectônica através da petrografia (Dickinson, 1975; Dickinson \& Suczek, 1979); geoquímica mineral (Morton, 1991; Morton \& Hallsworth, 1994; Mange \& Morton, 2007); geocronologia U-Pb em zircões detríticos (Roback \& Walker, 1995; Morton et al., 1996; Sircombe, 1999; Cawood \& Nemchin, 2000; Fedo et al., 2003, Link et al., 2005; Zhao et al., 2013; Fornelli et al., 2015;) e geoquímica de rocha total (Nesbitt \& Young, 1982; Bhatia \& Crook, 1986; Fedo et al., 1995; Bauluz et al., 2000; Jorge et al., 2013),esta última utilizada no presente trabalho.

A geoquímica de rocha total, no estudo de proveniência em bacias sedimentares, fornece informações que refletem a composição das áreas fontes, condições de intemperismo, seleção hidráulica, reciclagem e até mesmo ambiente tectônico das bacias (Jorge et al., 2013), através da interpretação dos elementos maiores e traço. De acordo com McLennan et al. (1990) e Rollinson (1993) elementos traços 
principalmente ETR, Th, Sc, Cr e Co são tidos como imóveis nos processos de transporte e intemperismo, sendo transportados exclusivamente nos componentes terrígenos dos sedimentos, refletindo a química da área fonte.

Foram estudados três afloramentos localizados no extremo norte da Sub-Bacia de Alagoas: Praia de Japaratinga, Barreiras do Boqueirão e Morro de Camaragibe. Esse são afloramentos clássicos e existe uma vasta literatura sobre sua estratigrafia e caracterização faciológica (Arienti, 1996, 2006; Siqueira, 2002; Lira, 2004; Nascimento \& Lima Filho, 2005). Suas rochas exibem o registro de parte da sedimentação rifte aptiana na Bacia de Sergipe-Alagoas (até então atribuídos à
Formação Maceió). É consenso que esses depósitos originaram-se por fluxos gravitacionais em um sistema flúvio-deltaicoturbidítico com pelo menos duas direções de paleocorrentes principais, SE, cujos sedimentos originaram-se da borda falhada do rifte aptiano, e SW, com sedimentos oriundos da região axial do rifte.

Este trabalho traz dados inéditos de geoquímica de rocha total nesses afloramentos além de novos estudos petrográficos. De forma a contribuir no estudo de proveniência dessas rochas, levando em consideração o posicionamento estratigráfico e as direções de paleocorrentes, complementando dados de geocronologia U-Pb em zircão detrítico (Almeida et al., em preparação).

\section{CONTEXTO GEOLÓGICO}

A Bacia de Sergipe-Alagoas é a bacia da margem leste brasileira que possui o registro sedimentar mais completo, apresentando todos os estágios evolutivos da ruptura do Pangea e surgimento do oceano Atlântico: Sinéclise Paleozoica, Pré-Rifte, Rifte, Transicional e Drifte (Feijó 1994; Mohriak et al. 1997; SouzaLima et al. 2002; Cruz 2008). Ela encontra-se limitada a norte com a Bacia PernambucoParaíba pelo Alto de Maragogi e a sul com a Bacia do Jacuípe pela Falha do Vaza Barris (Matos, 1999), enquanto que as duas sub-bacias são separadas pelo Alto de Japoatã-Penedo (Campos Neto et al., 2007).

As sub-bacias de Sergipe e Alagoas apresentam embasamentos distintos. A de Alagoas tem embasamento constituído marjoritariamente pelo Domínio PernambucoAlagoas, maior domínio da Província Borborema. Esse domínio está localizado entre a Zona de Cisalhamento Pernambuco e os terrenos neoproterozóicos Sergipano e Riacho do Pontal, dividindo-se em parte leste e oeste, separadas pela Bacia de Jatobá (Silva Filho et al. 2008). A porção leste representa cerca de $75 \%$ do complexo, sendo a região com ocorrência dos maiores batólitos graníticos da Província Borborema (Silva Filho et al. 2014). Em grande escala, o Domínio PernambucoAlagoas está subdivido em dois complexos (i) Cabrobró, formado por rochas supracrustrais e (ii) Belém do São Francisco, rochas ortoderivadas migmatizadas (Silva Filho et al.
2008). O embasamento da Sub-Bacia de Sergipe é representado pelo Sistema Orogênico Sergipano (Província Borborema) em praticamente toda a sua totalidade e pelo embasamento arqueano-paleoproterozóico (Craton do São Francisco), no extremo sul dessa sub-bacia.

Nesse trabalho foram estudados três afloramentos representativos de depósitos da Super Sequência Rifte da Bacia de SergipeAlagoas, Sub-Bacia de Alagoas, localizados no extremo norte do Estado homônimo. Essa Super Sequência se caracteriza por um estágio de subsidência mecânica, onde foram depositados os sedimentos do Grupo Coruripe, em ambiente continental e marinho restrito no Neoberriasiano ao Eoalbiano (Campos Neto et al., 2007).

As formações Feliz Deserto (Perrella et al., 1963 segundo Schaller, 1969), lacustre-deltaica, e Penedo (Kreidler e Andery 1949 segundo Schaller 1969), fluvio-deltaica, foram depositadas no estiramento inicial do rifte e no primeiro pulso tectônico do rifte foram depositados os sedimentos lacustres da Formação Barra de Itiúba (Kreidler \& Andery, 1949 segundo Schaller, 1969), interdigitado com a Formação Penedo. A partir da idade local Eojiquiá os sedimentos alúvio-fluviais das formações Rio Pitanga (Schaller, 1969) conglomerados de borda da bacia, e Penedo passaram a adentrar no lago Barra de Itiúba (Campos Neto et al., 2007). Nas porções rasas da Sub-bacia de Sergipe, durante os 
períodos de baixo aporte sedimentar, foi depositada a Formação Morro do Chaves (Hartt, 1870), composta por coquinas de bivalves e ostracodes não marinhos.

Durante o segundo pulso de rifteamento a porção emersa sergipana e parte da porção terrestre alagoana foram soerguidas, restringindo a sedimentação ao bloco baixo da charneira e ao nordeste de Alagoas (Campos Neto et al., 2007).

Nesses baixos continuou a sedimentação das formações Morro do Chaves e Rio Pitanga (Sub-Bacia de Sergipe), e na SubBacia de Alagoas instalou-se o sistema alúvio-deltáico e lacustre da Formação Coqueiro Seco (Schaller, 1969), depositado concomitantemente aos conglomerados de borda da Formação Poção (Figueiredo, 1978 segundo Souza-Lima et al., 2002). O terceiro pulso do rifte é representado pela Formação Maceió (Petrobras 1960 segundo Souza-Lima et al., 2002) e representada por leques aluviais e sistemas turbidíticos lacustres de idade neoaptiana (Campos Neto et al., 2007).

Os afloramentos estudados (Figura 1) estão localizados nos municípios de Japaratinga (afloramentos Praia de Japaratinga e Barreiras do Boqueirão) e Passo de Camaragibe (afloramento Morro de Camaragibe) e são atribuídos na literatura à Formação Maceió. Litologicamente são caracterizados por conglomerados e arenitos imaturos, por vezes depositados em contato anguloso e erosivo sobre litologias mais finas que variam de argilito a siltito, e sendo sobrepostas por litotipos mais finos como folhelhos e ritmitos. Esses litotipos exibem duas direções de paleocorrentes principais, SW e SE, e são interpretados como depósitos de fluxos gravitacionais catastróficos.

$\mathrm{O}$ afloramento Praia de Japaratinga $\left(09^{\circ} 05^{\prime} 50,24\right.$ 'S, $\left.35^{\circ} 15^{\prime} 31,52^{\prime \prime} \mathrm{W}\right)$ é uma falésia com cerca de $200 \mathrm{~m}$ de extensão, apresentando direção NNE-SSW $\left(10^{\circ}\right)$ com mergulho médio de de suas camadas $6^{\circ}$ para SW. Arienti (1996) afirma uma medida de paleocorrente para SW com mergulho das estratificações em $20^{\circ}$.

$\mathrm{O}$ afloramento apresenta basicamente quatro fácies, detalhadas em Almeida (2016). Na base encontram-se por argilitos a siltitos esverdeados ricos em conchostráceos com contato abruto a erosivo com o estrato superior formado por arenito médio a grosso, cinza claro, moderadamente selecionado, com estratificação oblíqua em baixo ângulo.

Essa fácies apresenta uma continuidade vertical inferior a $40 \mathrm{~cm}$ e continuidade lateral de aproximadamente $3 \mathrm{~m}$, sua estratificação apresenta paleocorrente dominante para SW e é sucedida em contato abrupto/erosivo por arenito conglomerático cinza claro esverdeado, mal selecionado, com seixos e matacões bem arredondados de granitoides e clastos achatados de folhelhos esverdeados ligeiramente orientados no sentido da estratificação.

Essa camada é formada por corpos amalgamados com estratificações sigmoidais de pequeno porte que gradam lateralmente para estratificações oblíquas de baixo ângulo também com paleocorrente predominante para $\mathrm{SW}$, apresenta boa continuidade lateral em todo o afloramento.

Todo esse pacote é cortado por uma feição canalizada constituída por paraconglomerado de matriz arenosa muito grossa com gradação normal para o topo, de cor alaranjada, maciço próximo à base, passando a uma insipiente estratificação oblíqua acanalada em direção ao topo que apresenta blocos e seixos de folhelhos cinza esverdeados deformados e ocasionalmente seixos granitoides, dispostos de maneira caótica.

Essa fácies apresenta uma paleocorrente de direção SE, medida pela estratificação oblíqua acanalada do topo.

Esse conjunto de fáceis pode ser interpretado como a porção mais proximal de um sistema flúvio-deltaico periodicamente afetado por cheias catastróficas que exibe uma sucessão de fácies de em prodelta na base, seguida por uma progradação de fácies fluviais de paleocorrente SW que, por sua vez, são erodidas por uma feição canalizada de sedimentação por cheia catastrófica com paleocorrente dominante SE.

$\mathrm{O}$ afloramento Barreiras do Boqueirão (0907’34,25”S, $\left.35^{\circ} 16^{\prime} 50,14^{\prime \prime} \mathrm{W}\right)$ possui continuidade lateral de cerca de $100 \mathrm{~m}$, com direção NE-SW de aproximadamente $40^{\circ}$ e mergulho regional de $12^{\circ}$ para SW. As paleocorrentes possuem direção predominante SW com mergulho de estratificação entre 14 a $25^{\circ}$ (Arienti, 1996). 

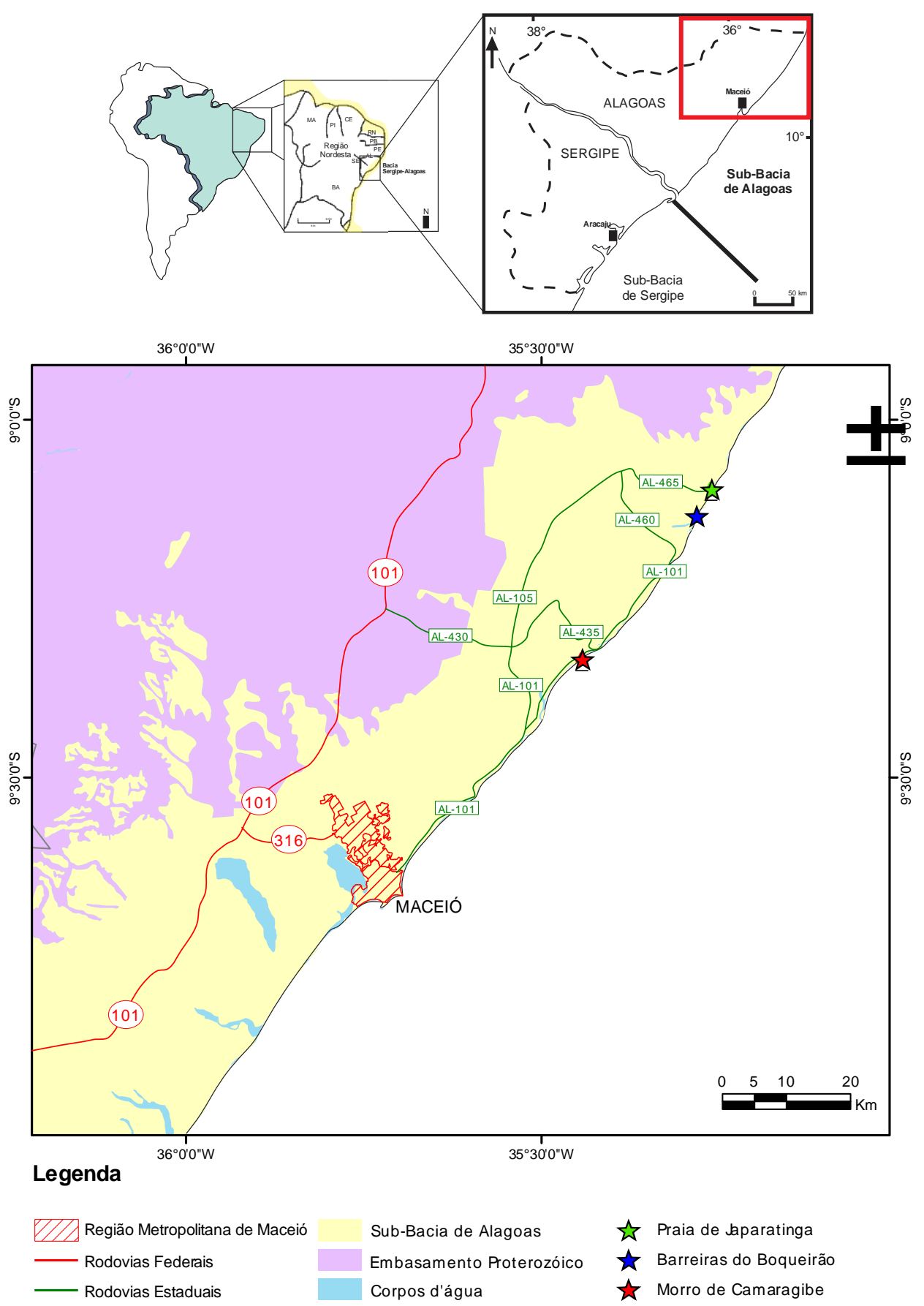

Figura 1 - Mapa de localização dos afloramentos estudados. Mapa regional modificado de Carvalho et al. (2006).

São observadas seis fácies nesse afloramento, conforme Almeida (2016). Na base encontra-se um arenito grosso cinza esverdeado maciço intensamente fluidizado, provavelmente equivalente às fácies arenosas do afloramento Praia de Japaratinga, o que não pode ser inferido com certeza devido à fluidização que obliterou as estruturas sedimentares. Sobre essa fácies observa-se um arenito médio a grosso de cor creme avermelhado com estratificação cruzada sigmoidal de grande porte, internamente à sigmoide, os estratos são marcados por gradação normal (grânulo a areia média) com alguns intraclastos milimétricos seguindo o mergulho da estratificação, com paleocorrente indicando transporte para SW.

Entre essas duas primeiras fácies do afloramento é possível observar um lente de siltito esverdeado rico em matéria orgânica com continuidade lateral intermitente e apresentando no máximo $10 \mathrm{~cm}$ de espessura. Sobre esse conjunto encontra-se uma feição canalizada semelhante ao paraconglomerado encontrado no afloramento Praia de Japaratinga composta por arenitos grossos a muito grossos de cor alaranjada contendo seixos de folhelhos, siltitos e granitóides que se interdigita lateralmente e grada para um 
arenito grosso a muito grosso de gradação normal e acamamento em baixo ângulo, que passa verticalmente para arenito finos a muito fino com laminações cruzadas cavalgantes, a paleocorrente nessa fácies é dominante SE. Sobre essa sequência arenosa encontra-se um folhelho escuro laminado rico em matéria orgânica com cerca de $50 \mathrm{~cm}$ de espessura.

Esse afloramento representa provavelmente a porção dominantemente deltáica do sistema fluvio-deltáico descrito para o afloramento Praia de Japaratinga e exibe, da base para o topo, fácies unidirecionais de domínio fluvial, fácies de siltito de uma provável retração do sistema, fácies de barras de desembocadura de frente deltaica representada pela estratificação sigmoidal de grande porte. Essa geometria é sobreposta por fácies arenosas canalizadas representando os fluxos canalizados catastróficos com direção SE que se interdigita a arenito grosso a muito grosso com granoascendência normal, interpretada como uma diminuição da energia do sistema. O folhelho escuro indica um período de anoxia no sistema.

O afloramento de Morro de Camaragibe $\left(09^{\circ} 20^{\prime} 06,43^{\prime \prime} \mathrm{S}, 35^{\circ} 26^{\prime} 25,97^{\prime \prime} \mathrm{W}\right)$ apresentase como um anticlinal com extensão de aproximadamente $800 \mathrm{~m}$ com uma complexa arquitetura estrutural que dificulta a correlação e interpretação de todo o conjunto de fácies ao longo do afloramento. Para melhor entendimento, o afloramento pode ser compartimentado em três partes principais: norte, central e sul. O setor norte do anticlinal apresenta um mergulho das camadas variando entre $15^{\circ}$ a $20^{\circ}$ para SW com direção preferencial NW/SE, já o setor sul mostra um mergulho de camadas entre $6^{\circ}$ a $15^{\circ}$ para NW, com direção preferencial NE/SW (Siqueira, 2002), enquanto que a porção central não apresenta grande mergulho aparente. As descrições detalhadas das fácies de cada setor são vistas em Almeida (2016).

A porção norte do afloramento apresenta, na base, uma fácies interacamadada com alternância de lâminas de arenito fino com ripples e siltito argiloso cinza escuro de aspecto maciço a laminado e rico em matéria orgânica para o topo, com estruturas em chama, apresentando ripples em geral unidirecionais, para sudoeste. Em seguida pode-se observar um paraconglomerado de matriz arenosa média a grossa contendo clastos e blocos de lamitos aparentemente oriundos do rompimento de camadas de folhelhos (deformação intraestratal), na base da camada observa-se um plano de deslizamento, a partir do qual se desenvolvem dobras centimétricas a decimétricas, aparentemente com um componente de vergência para SW.

Acima dessas fácies encontra-se um arenito grosso conglomerático mal selecionado acamadado e com porções gradacionais, por vezes exibindo estratificação tabular e passam a estratificação plano-paralela no topo. Interna a essa fácies há feições canalizadas compostas por paraconglomerado de matriz arenosa média a grossa contendo clastos de folhelhos, siltitos e arenitos. Além disso, é possível observar a presença de corpos lenticulares de siltitos esverdeados com cerca de $15 \mathrm{~cm}$ de espessura, semelhantes aos presentes no afloramento Barreiras do Boqueirão.

A parte central desse afloramento possui basicamente três fácies: arenito fino a médio, moderadamente selecionado, com estratificação plano-paralela na base da seção, passando para ripples no topo, com vários fragmentos de matéria orgânica escura; paraconglomerado de matriz arenosa de composição lítica, contendo grânulos e seixos de granitóides, blocos de arenito fino a médio, blocos de siltitos e arenitos vermelhos e de lamitos cinza escuro com matriz mal selecionada preenchendo feição canalizada e; arenito muito grosso na base do estrato, passando a grosso e por vezes a médio em direção ao topo, muito mal selecionado, maciço, com blocos de lamitos dispersos no topo.

$\mathrm{Na}$ porção sul observam-se arenito cinza escuro, maciço, muito mal selecionado, com blocos dispersos decimétricos de lamitos e carvão, próximo ao topo dessa fácies há uma porção fina com climbing ripples fluidizadas e cristas colapsadas. Sobre esse pacote encontrase uma camada de arenito médio a grosso maciço de coloração cinza esverdeada com fragmentos de carvão dispersos que grada para um arenito fino com climbing ripples de paleocorrente SW. Há também uma camada de ritmito formado por intercalação de siltito argiloso rico em matéria orgânica e lentes de arenitos finos e camadas de siltito margosos, cinza claro. Na base da porção mais distal do 
afloramento observa-se camadas de folhelho escuro, rico em matéria orgânica com boa fissilidade, contendo fragmentos de carvão e fósseis de peixes. De um modo geral, as associações de fácies presentes nos 3 setores supracitados, caracterizam um sistema turbidítico com no mínimo três domínios de geometrias deposicionais distintas: a) um domínio proximal de fácies canalizadas (norte); b) um domínio intermediário de geometrias lobadas com maior continuidade dos corpos arenosos (central), e c) um domínio distal com presença de corpos menos espessos de arenitos finos interacamadados com lamitos, caracte-rizando as franjas tubidíticas (sul). A figura 2 exibe perfis esquemáticos dos afloramentos estudados.

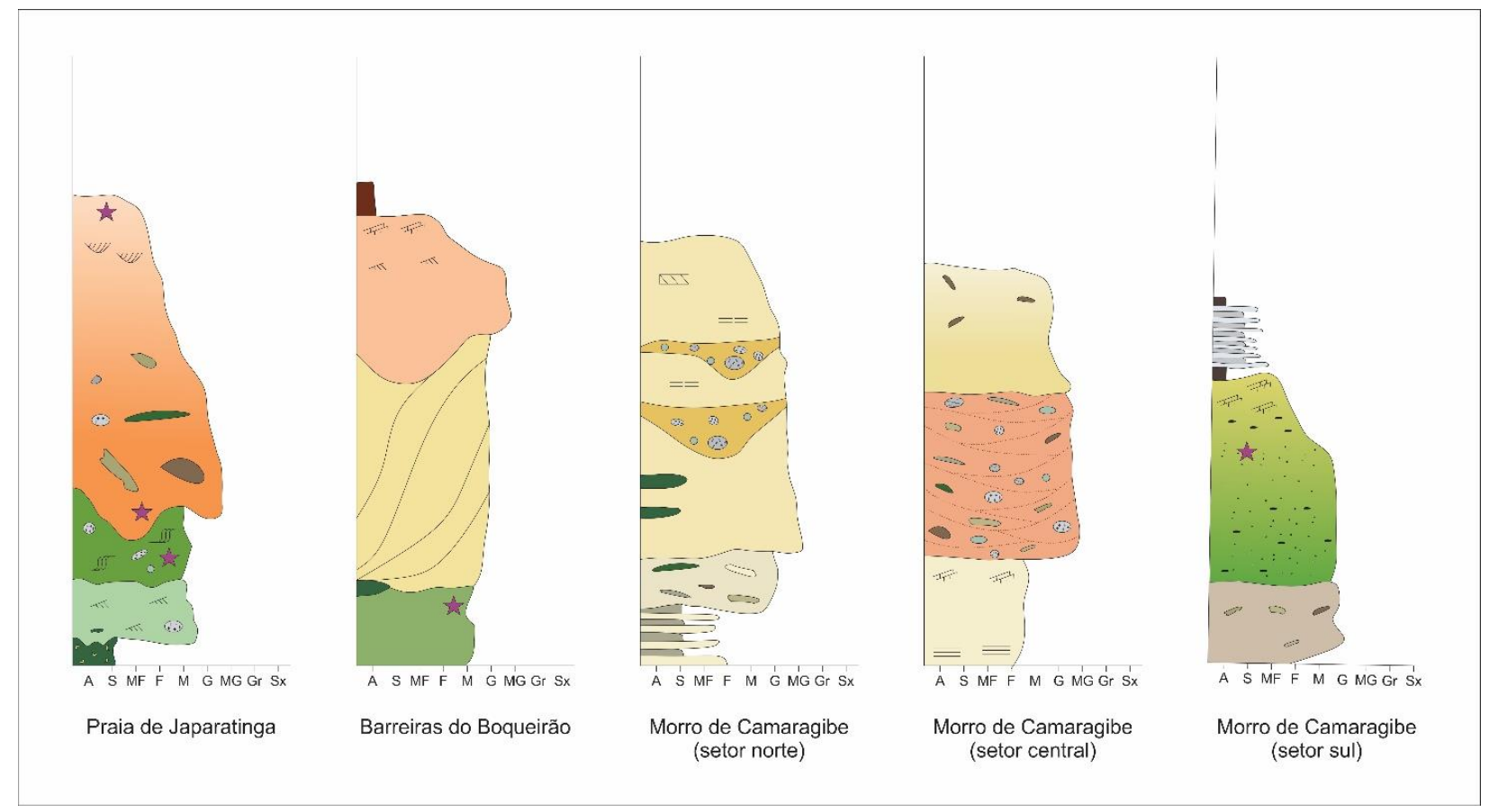

Figura 2 - Perfis estratigráficos esquemáticos (sem escala vertical) mostrando as principais fácies dos afloramentos estudados. As estrelas indicam fácies amostradas para análise química. (A: argila; S: silte; MF: areia muito fina; F: areia fina; M: areia média; G: areia grossa; MG: areia muito grossa; Gr: grânulo; Sx: seixo).

\section{AMOSTRAGEM E TÉCNICAS ANALÍTICAS}

Cinco amostras foram selecionadas para análise geoquímica: três do afloramento Praia de Japaratinga, uma de Barreiras do Boqueirão e uma de Morros de Camaragibe. As análises foram realizadas no Acme Analytical Laboratories Ltda, Canadá. Foram dosados óxidos dos elementos maiores $\left(\mathrm{SiO}_{2}, \mathrm{TiO}_{2}\right.$, $\mathrm{Al}_{2} \mathrm{O}_{3}, \mathrm{Fe}_{2} \mathrm{O}_{3}, \mathrm{MnO}, \mathrm{MgO}, \mathrm{CaO}, \mathrm{Na}_{2} \mathrm{O}, \mathrm{K}_{2} \mathrm{O}$ $\mathrm{Cr}_{2} \mathrm{O}_{3}$ e $\mathrm{P}_{2} \mathrm{O}_{5}$ ), elementos menores e os elementos traços. Os resultados das análises foram tratados com auxílio do software GCDkit ${ }^{\circledR}$ (Geochemical Data Toolkit for Windows 2.3) de Janoušek et al. (2006).

No afloramento de Praia de Japaratinga foi selecionada uma amostra (JPT-01) representativa do arenito conglomerático cinza claro esverdeado com estratificação em baixo ângulo (Figura 3A), apresentando paleocorrente dominante para SW. As outras duas amostras foram selecionadas da fácies composta por paraconglomerado de paleocorrente SE (Figura 3B). Uma das amostras amostra (JPT-02) foi extraída da porção mais fina no topo dessa sequência enquanto que a terceira amostra foi extraída da sua matriz na porção basal mais grossa do paraconglomerado (JPT-03).

A amostra selecionada no afloramento de Barreiras do Boqueirão (BOQ-01) corresponde a fácies de arenito grosso cinza esverdeado maciço (Figura 3C). Provavelmente equivalente à fácies de amostragem JPT-03 no afloramento Praia de Japaratinga, o que não pode ser inferido com certeza devido à fluidização que obliterou as estruturas sedimentares. Por fim, a amostra selecionada para o estudo no afloramento Morro de Camaragibe (CAM-09) é representativa do arenito médio a grosso esverdeado (Figura 3D) que apresenta gradação normal para um arenito fino com climbing ripples apresentando paleocorrente para SW.

De forma a complementar às análises geoquímicas foi realizado estudo petrográfico em três amostras do afloramento Barreiras do 
Boqueirão, duas do afloramento Praia de Japaratinga e cinco do afloramento Morro de Camaragibe, totalizando dez lâminas que foram utilizadas para caracterização de composição, aspectos texturais e análise de proveniência. $\mathrm{Na}$ análise petrográfica foi utilizada a contagem
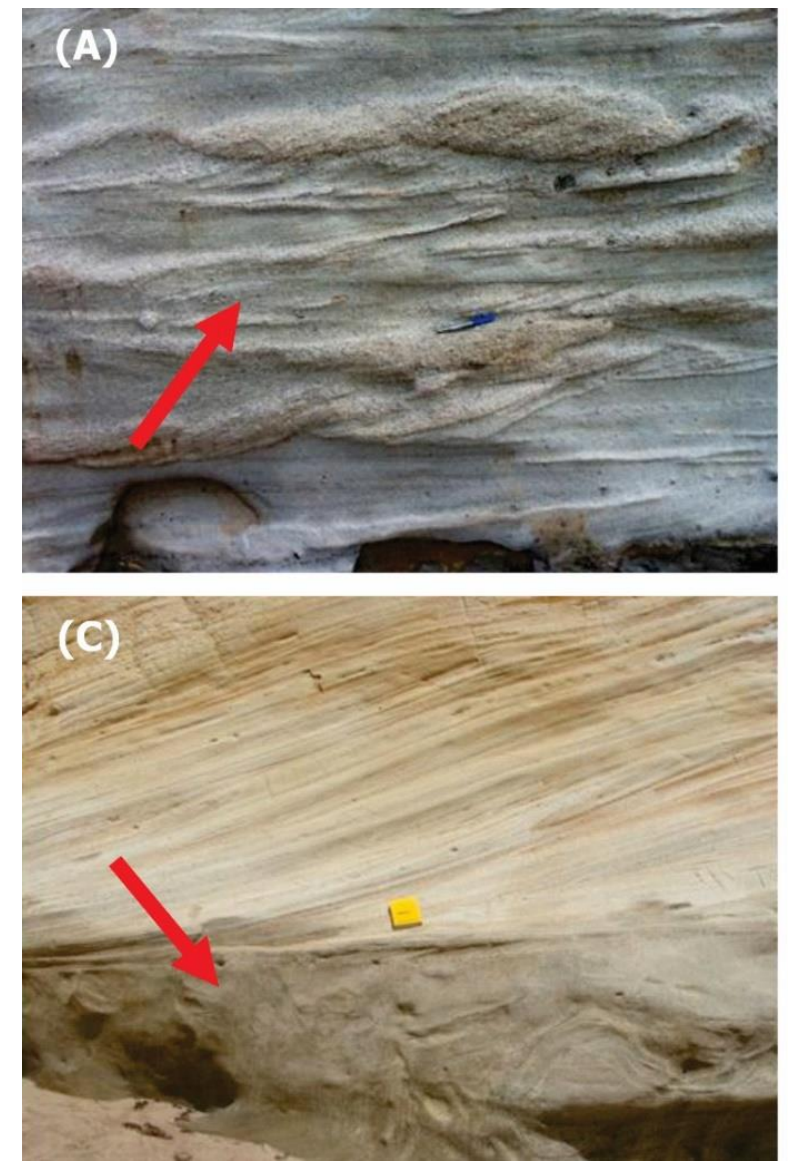

Figura 3 - Fácies amostradas nesse trabalho. (A) Arenito conglomerático da amostra JPT-01 (b) Paraconglomerado alaranjado das amostras JPT-02 e JPT-03 (C) Arenito maciço fluidizado da amostra BOQ-01 (D) Arenito esverdeado da amostra CAM-09.

\section{PETROGRAFIA}

Os litotipos dos afloramentos estudados são classificados como arcósios conforme Folk (1968), conforme o diagrama ternário da figura 4, apresentando uma composição original média para os afloramentos de Praia de Japaratinga, Barreiras do Boqueirão e Morros de Camaragibe de $\mathrm{Q}_{46,91} \mathrm{~F}_{51,03} \mathrm{~L}_{2,07}$, $\mathrm{Q}_{34,70} \mathrm{~F}_{64,65} \mathrm{~L}_{0,66}$ e $\mathrm{Q}_{45,82} \mathrm{~F}_{53,28} \mathrm{~L}_{0,90}$ respectivamente, onde $\mathrm{Q}$ corresponde ao percentual de quartzo total, $\mathrm{F}$ ao percentual de grãos de feldspato detrítico juntamente com fragmentos graníticos e gnáissicos, e L corresponde a todos os fragmentos líticos finos.

De uma maneira geral os arenitos são texturalmente e composicionalmente imaturos (Figura 5) e apresentam grãos de quartzo em sua maioria monocristalinos com extinção reta, modal de Gazzi-Dickinson (Zuffa, 1985). A classificação textural e composicional das rochas seguiu a terminologia descrita por Folk (1968) enquanto que a classificação de proveniência dessas rochas seguiu a classificação de Dickinson \& Suczek (1979) e Dickinson (1985).
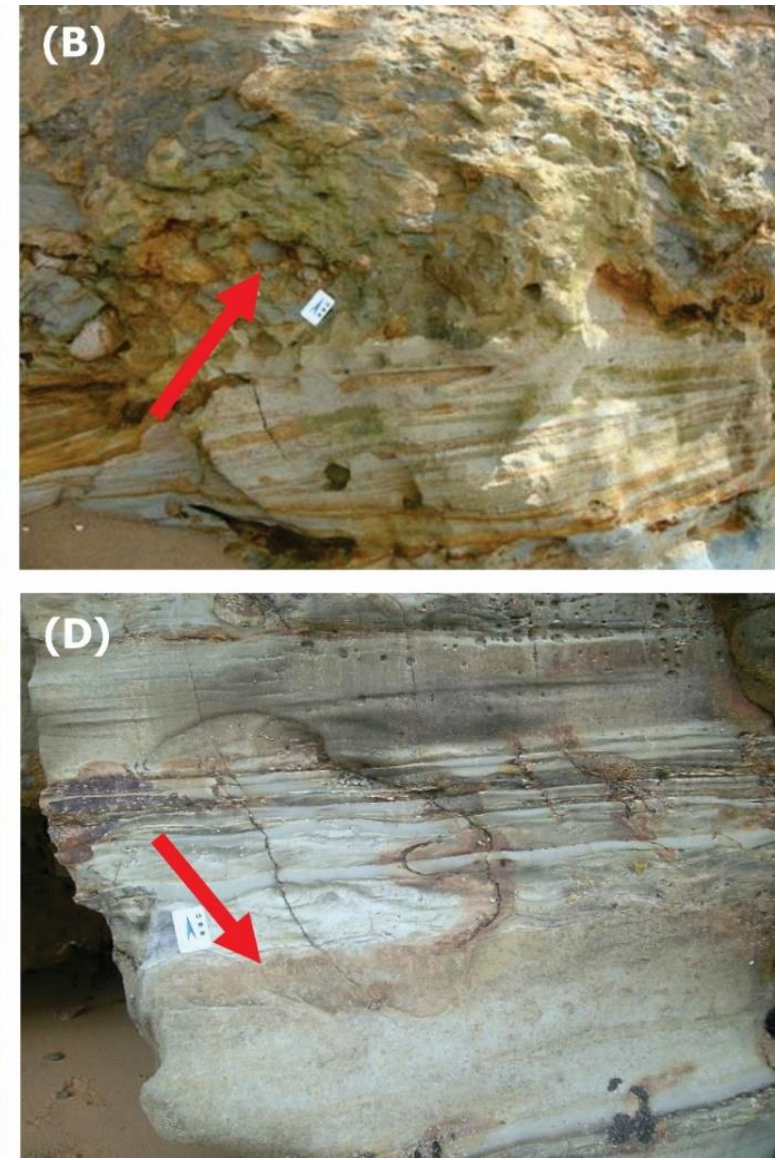


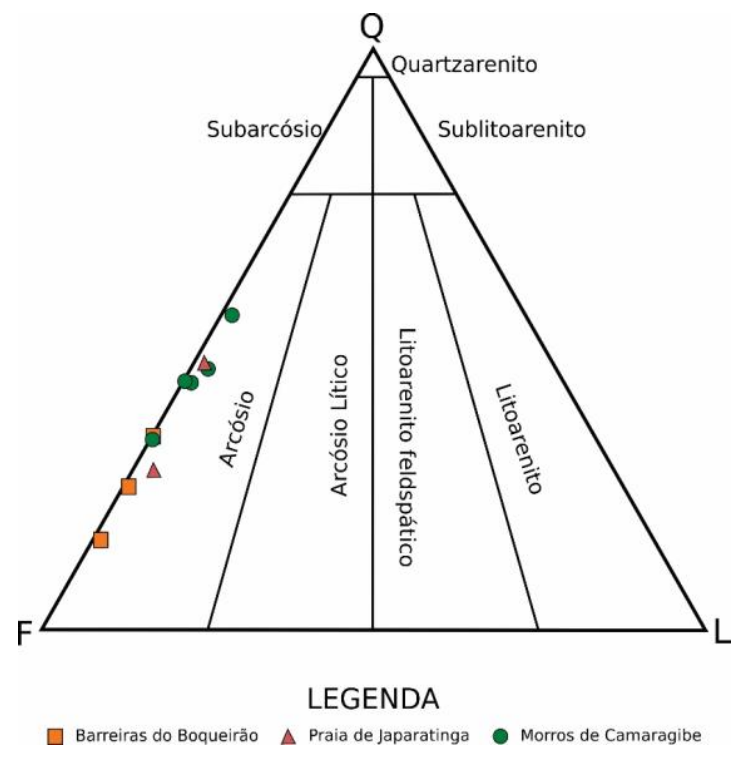

Figura 4 - Diagrama composicional de Folk (1968).

Os constituintes diagenéticos identificados em ordem de abundância são: ilita/esmectita (I/S), caulinita, óxido/hidróxidos de ferro, albita, leucoxênio, argila indiferenciada, argila infiltrada, pirita e quartzo. Calcita diagenética aparece apenas no afloramento Morro de Camaragibe em quantidade significativa. Como maior importância para esse estudo tempo a presença de ilita/esmectita, que ocorre com expres-sividade média de $14,27 \%$ e apresentase como uma massa uniforme entre os grãos, compondo uma matriz deposicional e substituindo grãos de feldspato detrítico, caulinita ocorrendo principalmente intragranular substituindo grãos de feldspato e calcita, que aparece nos litotipos do afloramento de Morro de Camaragibe, com média geral de $1,90 \%$ chegando ao valor máximo de $8,99 \%$.

A porosidade petrográfica apresenta uma média de $16,13 \%$, com valores variando entre $10,99 \%$ e $22,67 \%$. É constituída principalmente por poros intergranulares ampliados por dissolução além de poros intragranulares em grãos de feldspato. Os gráficos de Dickinson (1985) sugerem que as amostras estudadas são provenientes principalmente de embasamento soerguido (Figura 6), em ambiente tectonicamente instável e área fonte próxima ao local de deposição, o que é confirmado pela baixa maturidade textural e mineralógica dos litotipos.
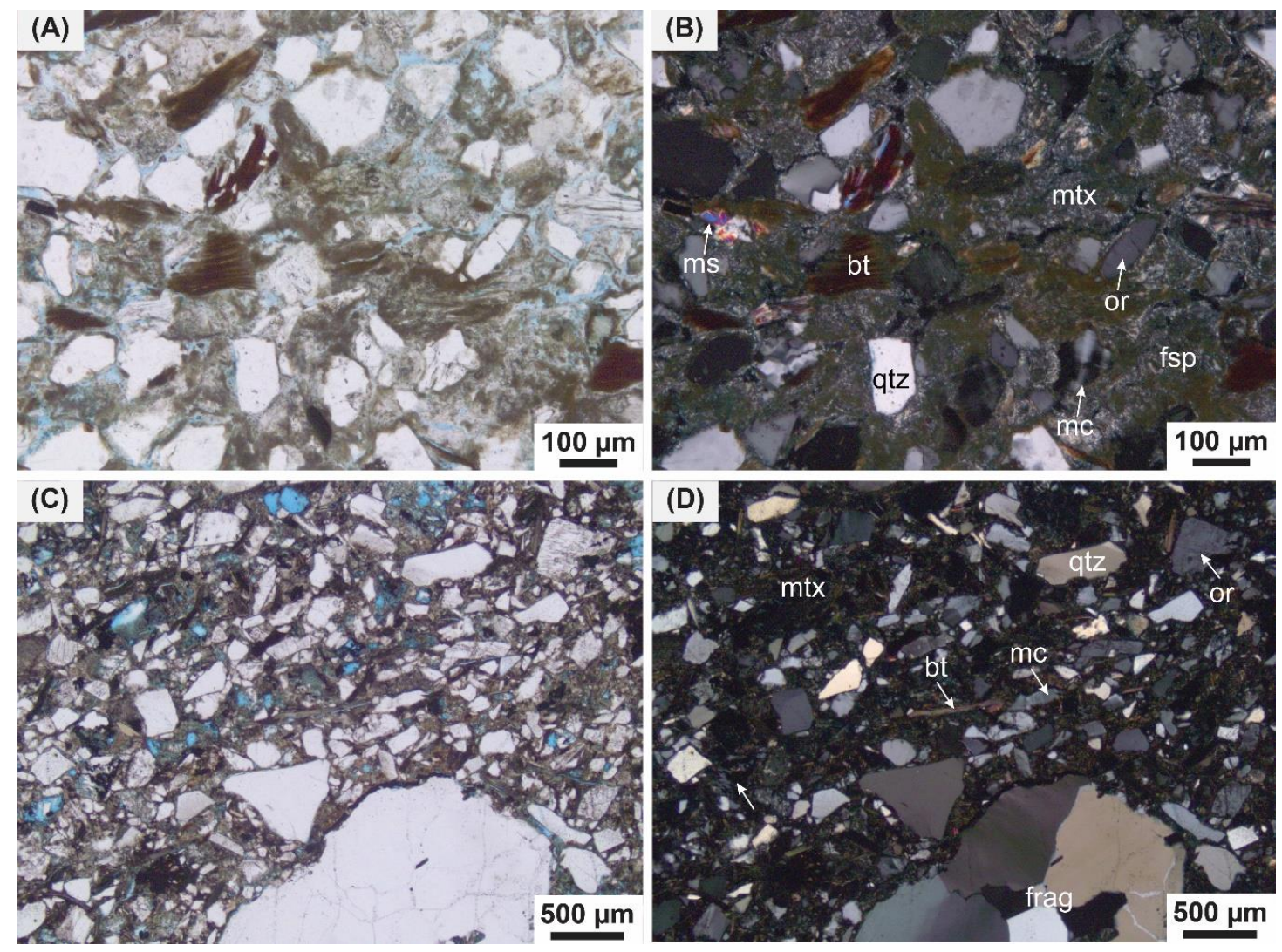

Figura 5 - Fotomicrografias dos aspectos texturais (coluna da esquerda, nicóis paralelos) e composicionais (coluna da direita, nicóis cruzados) das fácies arenito médio a grosso esverdeado (amostra CAM-09), afloramento Morro de Camaragibe (A e B), Paraconglomerado alaranjado (amostras JPT-02 e 03), afloramento Japaratinga (C e D) e arenito grosso maciço fluidizado (amostra BOQ-01), afloramento Barreiras do Boqueirão (E e F). Legenda: (bt) biotita, (frag) fragmento de rocha granitoide, (fsp) feldspato alterado, (mc) microclínio, (ms) muscovita. (mtx) matriz argilosa alterada, (or) ortoclásio, (qtz) quartzo. 
Tabela 1. Composição de rocha total das amostras selecionadas.

\begin{tabular}{|c|c|c|c|c|c|}
\hline Amostra \% & JPT-01 & JPT-02 & JPT-03 & BOQ-01 & CAM-09 \\
\hline $\mathrm{SiO}_{2}$ & 63,38 & 63,76 & 72,60 & 71,06 & 61,56 \\
\hline $\mathrm{Al}_{2} \mathrm{O}_{3}$ & 15,86 & 10,89 & 12,16 & 13,48 & 13,96 \\
\hline $\mathrm{Fe}_{2} \mathrm{O}_{3}$ & 3,82 & 2,06 & 2,24 & 1,63 & 3,90 \\
\hline MgO & 1,41 & 1,12 & 1,03 & 1,25 & 3,10 \\
\hline $\mathrm{CaO}$ & 0,12 & 6,40 & 0,12 & 0,14 & 1,82 \\
\hline $\mathrm{Na}_{2} \mathrm{O}$ & 0,40 & 1,34 & 0,48 & 1,14 & 1,68 \\
\hline $\mathrm{K}_{2} \mathrm{O}$ & 4,23 & 4,44 & 4,94 & 4,71 & 5,90 \\
\hline $\mathrm{TiO}_{2}$ & 0,73 & 0,24 & 0,28 & 0,40 & 0,65 \\
\hline $\mathbf{P}_{2} \mathbf{O}_{5}$ & 0,21 & 0,08 & 0,08 & 0,07 & 0,35 \\
\hline MnO & $<0,01$ & 0,10 & 0,02 & 0,02 & 0,06 \\
\hline $\mathrm{Cr}_{2} \mathrm{O}_{3}$ & 0,008 & 0,003 & 0,002 & 0,004 & 0,003 \\
\hline TOT/C & 0,13 & 1,44 & 0,03 & 0,04 & 0,54 \\
\hline TOT/S & 0,05 & 0,31 & 0,12 & 0,05 & 0,25 \\
\hline LOI & 9,4 & 9,4 & 5,8 & 5,8 & 6,7 \\
\hline Total & 99,56 & 99,81 & 99,79 & 99,70 & 99,72 \\
\hline \multicolumn{6}{|l|}{ ppm } \\
\hline $\mathbf{N i}$ & $<20$ & 22 & 23 & $<20$ & $<20$ \\
\hline Sc & 9 & 3 & 3 & 5 & 8 \\
\hline $\mathbf{B a}$ & 2027 & 1075 & 1114 & 1344 & 1047 \\
\hline Be & 9 & 6 & 2 & $<1$ & $<1$ \\
\hline Co & 1,8 & 6,1 & 4,8 & 3,4 & 9,4 \\
\hline Cs & 2,9 & 1,9 & 2,4 & 1,5 & 7,3 \\
\hline Ga & 20,6 & 9,5 & 12,8 & 13,1 & 15,4 \\
\hline Hf & 10,2 & 3,3 & 3,8 & 6,3 & 8,0 \\
\hline $\mathbf{N b}$ & 22,0 & 8,6 & 9,3 & 12,8 & 14,9 \\
\hline $\mathbf{R b}$ & 142,4 & 121,0 & 135,0 & 127,5 & 159,1 \\
\hline Sn & 3 & $<1$ & 2 & 8 & 2 \\
\hline $\mathbf{S r}$ & 227,5 & 146,2 & 122,2 & 160,6 & 188,7 \\
\hline $\mathbf{T a}$ & 1,9 & 0,8 & 1,3 & 1,7 & 1,4 \\
\hline Th & 19,0 & 7,6 & 9,1 & 10,5 & 17,2 \\
\hline $\mathbf{U}$ & 8,4 & 1,3 & 3,3 & 1,8 & 4,4 \\
\hline $\mathbf{V}$ & 74 & 34 & 40 & 42 & 64 \\
\hline $\mathbf{W}$ & 2,4 & 0,5 & 1,0 & 14,1 & 0,8 \\
\hline $\mathbf{Z r}$ & 405,0 & 133,5 & 152,2 & 230,8 & 290,6 \\
\hline $\mathbf{Y}$ & 49,9 & 9,2 & 10,6 & 37,8 & 21,0 \\
\hline Mo & 0,3 & 0,4 & 0,5 & 0,2 & 0,6 \\
\hline $\mathbf{C u}$ & 14,5 & 3,9 & 5,7 & 3,7 & 38,4 \\
\hline $\mathbf{P b}$ & 30,2 & 6,4 & 8,3 & 8,4 & 6,0 \\
\hline Zn & 13 & 27 & 53 & 49 & 60 \\
\hline $\mathrm{Ni}$ & 2,8 & 12,6 & 7,4 & 6,2 & 19,5 \\
\hline \multicolumn{6}{|l|}{ ppm } \\
\hline La & 95,3 & 20,7 & 24,7 & 81,6 & 33,9 \\
\hline $\mathrm{Ce}$ & 224,9 & 42,6 & 53,9 & 186,8 & 69,1 \\
\hline Pr & 29,37 & 4,35 & 5,67 & 20,41 & 7,64 \\
\hline Nd & 128,4 & 15,1 & 21,4 & 76,2 & 27,2 \\
\hline Sm & 26,70 & 2,31 & 3,68 & 13,50 & 4,96 \\
\hline Eu & 5,44 & 0,62 & 0,88 & 2,92 & 1,09 \\
\hline Gd & 21,04 & 2,06 & 2,93 & 11,02 & 4,33 \\
\hline $\mathbf{T b}$ & 2,76 & 0,27 & 0,38 & 1,50 & 0,73 \\
\hline Dy & 12,40 & 1,69 & 1,97 & 7,44 & 3,74 \\
\hline Ho & 1,85 & 0,31 & 0,34 & 1,41 & 0,74 \\
\hline $\mathbf{E r}$ & 4,21 & 0,87 & 1,10 & 3,25 & 2,19 \\
\hline Tm & 0,55 & 0,14 & 0,14 & 0,54 & 0,33 \\
\hline $\mathbf{Y b}$ & 3,55 & 1,06 & 1,02 & 3,43 & 2,31 \\
\hline Lu & 0,52 & 0,15 & 0,15 & 0,51 & 0,36 \\
\hline
\end{tabular}




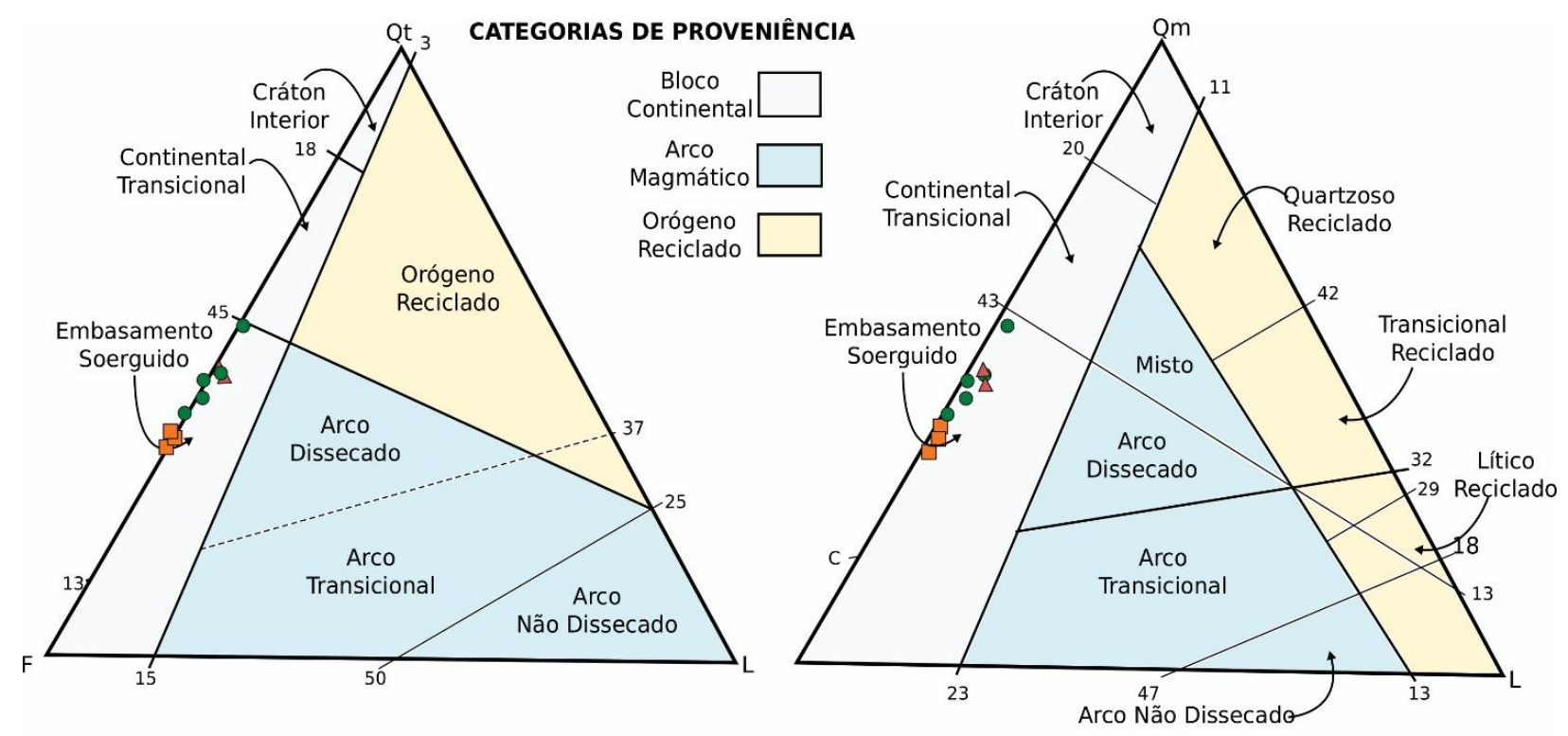

\section{LEGENDA}

Figura 6 - Gráficos de Dickinson (1985) com as proveniências das amostras descritas.

\section{GEOQUÍMICA DE ROCHA TOTAL}

\section{Elementos Maiores}

A média de $\mathrm{SiO}_{2}$ nas amostras é cerca de $66,47 \%$ com maior proporção na amostra JPT-03 com $72,60 \%$ enquanto que a porcentagem média de $\mathrm{Al}_{2} \mathrm{O}_{3}$ nas amostras é de
$13,27 \%$ com máximo de $15,86 \%$ na amostra JPT-01, refletindo a mineralogia das amostras estudadas (Tabela 1). As amostras têm uma razão média de $\mathrm{K}_{2} \mathrm{O} / \mathrm{Na}_{2} \mathrm{O}$ de 6,36 (Tabela 2).

Tabela 2. Índices de alteração para as amostras selecionadas.

\begin{tabular}{c|c|c|c|c|c}
\hline Amostra & JPT-01 & JPT-02 & JPT-03 & BOQ-01 & CAM-09 \\
\hline CIA & 77,43 & 65,08 & 69,17 & 69,74 & 64,79 \\
\hline PIA & 96,73 & 82,13 & 93,78 & 88,50 & 82,70 \\
\hline $\mathbf{K}_{2} \mathbf{O} / \mathbf{N a}_{2} \mathbf{O}$ & 10,58 & 3,31 & 10,29 & 4,13 & 3,51 \\
\hline $\mathbf{K}_{2} \mathbf{O} / \mathbf{A l}_{2} \mathbf{O}_{3}$ & 0,27 & 0,41 & 0,41 & 0,35 & 0,42 \\
\hline
\end{tabular}

$\mathrm{CIA}=\left[\mathrm{Al}_{2} \mathrm{O}_{3} /\left(\mathrm{Al}_{2} \mathrm{O}_{3}+\mathrm{CaO}^{*}+\mathrm{Na}_{2} \mathrm{O}+\mathrm{K}_{2} \mathrm{O}\right)\right] \times 100$ (Nesbitt e Young, 1982)

$\mathrm{PIA}=\left[\left(\mathrm{Al}_{2} \mathrm{O}_{3}-\mathrm{K}_{2} \mathrm{O}\right) /\left(\mathrm{Al}_{2} \mathrm{O} 3+\mathrm{CaO} *+\mathrm{Na}_{2} \mathrm{O}-\mathrm{K}_{2} \mathrm{O}\right)\right] \times 100($ Fedo et al., 1995).

Comparando os valores médios da crosta continental superior (Upper Continental Crust ou UCC) de Taylor \& McLennan (1995) com a média das amostras (Figura 7) observa-se valores de $\mathrm{K}_{2} \mathrm{O}$ ligeiramente elevados para todas as amostras e uma depleção no restante dos elementos, especialmente para $\mathrm{MnO}, \mathrm{CaO}$ e $\mathrm{Na}_{2} \mathrm{O}$, com exceção da amostra JPT-02 que apresenta $\mathrm{MnO}$ e $\mathrm{CaO}$ acima da média da crosta continental superior (Taylor \& McLennan, 1995). Essa anomalia está de acordo com a proporção elevada de TOT/C, que incorpora esses elementos na formação de carbonatos nas rochas de granulometria mais fina e também de acordo com a petrografia, pois essa amostra corresponde à porção mais fina da matriz do paraconglomerado alaranjado. Comparando esses resultados com a petrografia, observa-se uma tendência de maiores valores de $\mathrm{Al}_{2} \mathrm{O}_{3}$ nas fácies com maior proporção de ilita-esmectita, correlacionando o aumento desse óxido ao grau de intemperismo.

Para medir o grau de intemperismo das amostras foram utilizados dois parâmetros (Tabela 2): (a) Índice de Alteração Química, CIA, (Nesbitt \& Young, 1982) e (b) Índice de Alteração do Plagioclásio, PIA, (Fedo et al., 1995). O CIA apresenta-se com uma média de 69,24 , estando próximo ao valor médio do folhelho (cf. Nesbitt \& Young, 1982) o que indica grande alteração desses arenitos com 


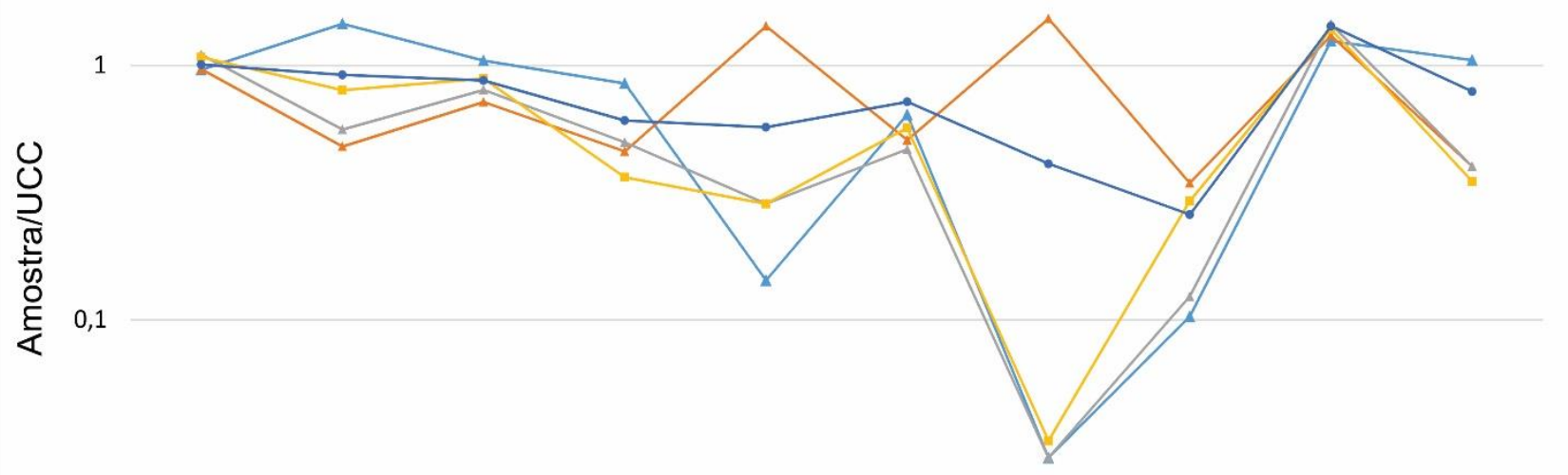

0,01

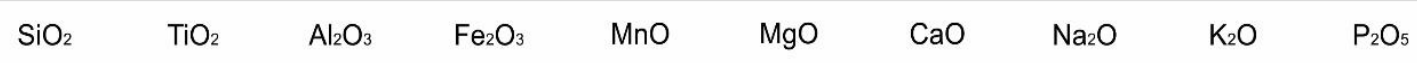

$$
\begin{aligned}
& \rightarrow \text { JPT-01 } \rightarrow \text { JPT-02 } \rightarrow \text { JPT-03 } \rightarrow \text {-BOQ-01 } \rightarrow \text {-CAM-09 }
\end{aligned}
$$

Figura 7 - Gráfico de elementos maiores normalizados pela crosta continental superior (Taylor \& McLennan, 1995).

presença de argilominerais de alteração, como foi constatado na descrição das lâminas petrográficas. Já a média do PIA foi de 88,77 , indicando alto grau de alteração dos plagioclásios, como também foi observado em microscopia óptica.

\section{Elementos Traço e ETR}

Os elementos traço (Figura 8A) exibem um empobrecimento em metais de transição (Sc, V, $\mathrm{Cr}$, Ni e Co) relativos à média da crosta continental superior para todas as amostras, o que pode ser indicativo de uma área fonte pobre em minerais ferro-magnesianos ou que esses elementos foram lixiviados pelos processos de intemperismo. Quanto aos elementos litófilos de alto raio iônico (LILE), com exceção do Cs, as amostras exibem um enriquecimento dos mesmos. A depleção do $\mathrm{Sr}$ nas amostras junto com o enriquecimento de $\mathrm{Rb}$ e $\mathrm{Ba}$ estão de acordo com a substituição e alteração dos feldspatos durante o intemperismo químico. Há uma correlação positiva entre $\mathrm{Zr}$-Th e $\mathrm{Nb}$ - $\mathrm{Ta}$, indicando que esses pares de elementos estão incorporados em zircão e minerais de titânio (cf. Jorge et al., 2013). Foi possível ainda identificar três grupos de amostras diferentes (Fig 8 B, C e D) de acordo com a semelhança composicional das amostras (a) JPT-02 E JPT-
03; (b) JPT-01 e BOQ-01 e (c) CAM-01, a semelhança entre JPT-01 e BOQ-01 corrobora com as interpretações de campo, dando mais argumentos para a correlação entre as fácies das amostras JPT-03 e BOQ-01.

Os elementos de terras raras (ETRs, Tabela 1) foram normalizados pelo Condrito de Nakamura (1974) e mostram que as amostras analisadas apresentam um enriquecimento maior em ETRs leves do que ETRs pesados (Figura 9 A). A anomalia de Eu apresenta-se mais evidente nas amostras JPT-01, BOQ-01 e CAM-01 do que nas amostras JPT-02 e JPT-03.

Os padrões apresentados permitem subdividir as amostras em dois grupos distintos, como mostram as figuras $9 \mathrm{~B}$ e $9 \mathrm{C}$ (a) JPT-01, BOQ-01 e CAM-01 e (b) JPT-02 e JPT-03, sendo mais uma vez coerente com as interpretações estratigráficas pois, para as fácies correspondentes às amostras JPT-01, BOQ-01 e CAM-01 a paleocorrente indica um transporte para SW enquanto que para as amostras JPT-02 e JPT-03 a paleocorrente foi medida em sentido aproximadamente ortogonal para SE. Esses dados evidenciam uma provável diferença de áreas fontes para os dois grupos observados. 
10 (A)

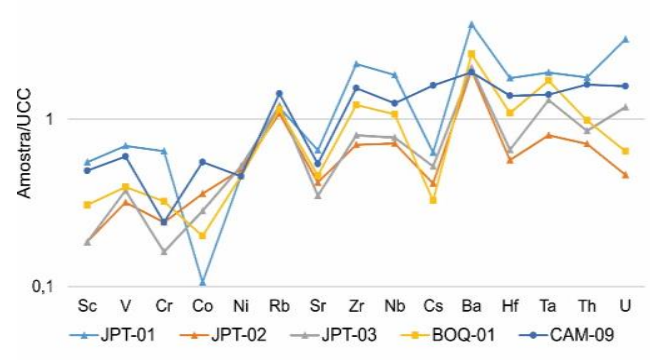

(C)

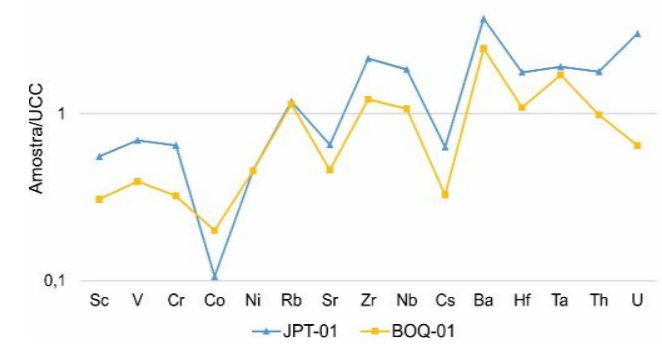

(B)

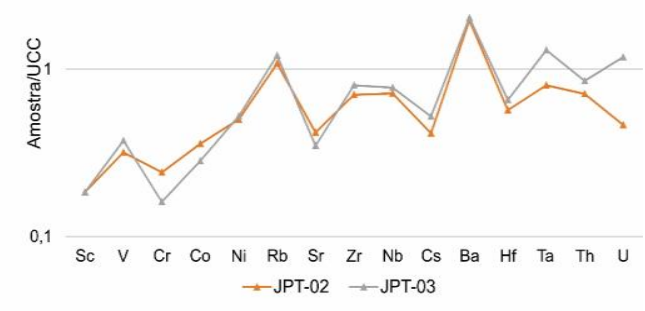

(D)

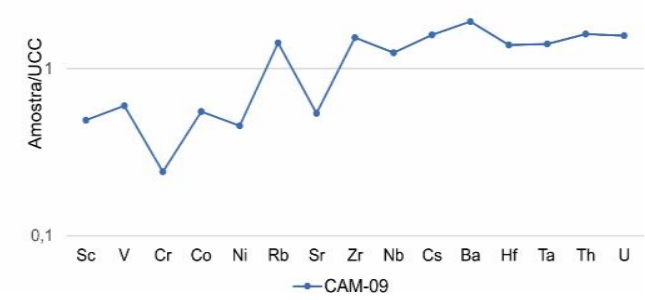

Figura 8 - (A) Gráfico de elementos traços normalizados pela crosta continental superior (Taylor \& McLennan 1995); (B) Padrões para as amostras JPT-02 e JPT-03; (C) Similaridade entre as amostras JPT-01 e BOQ-01; (D) Padrão da amostra CAM-09.

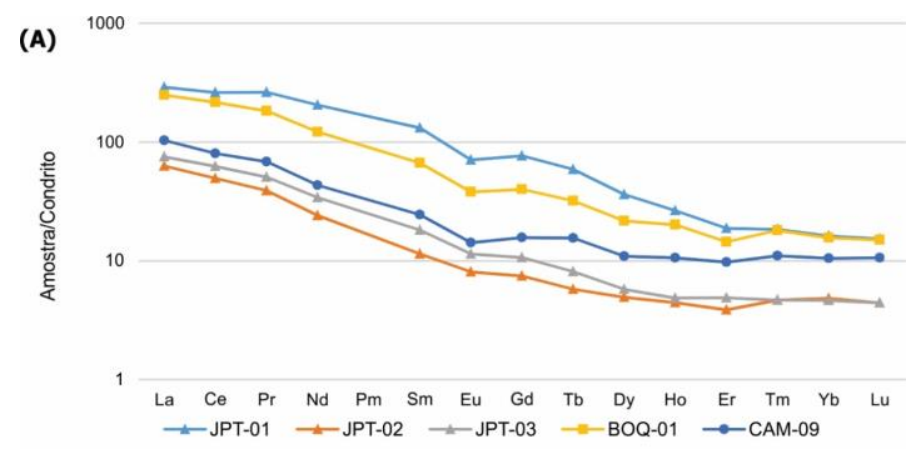

(B) 1000
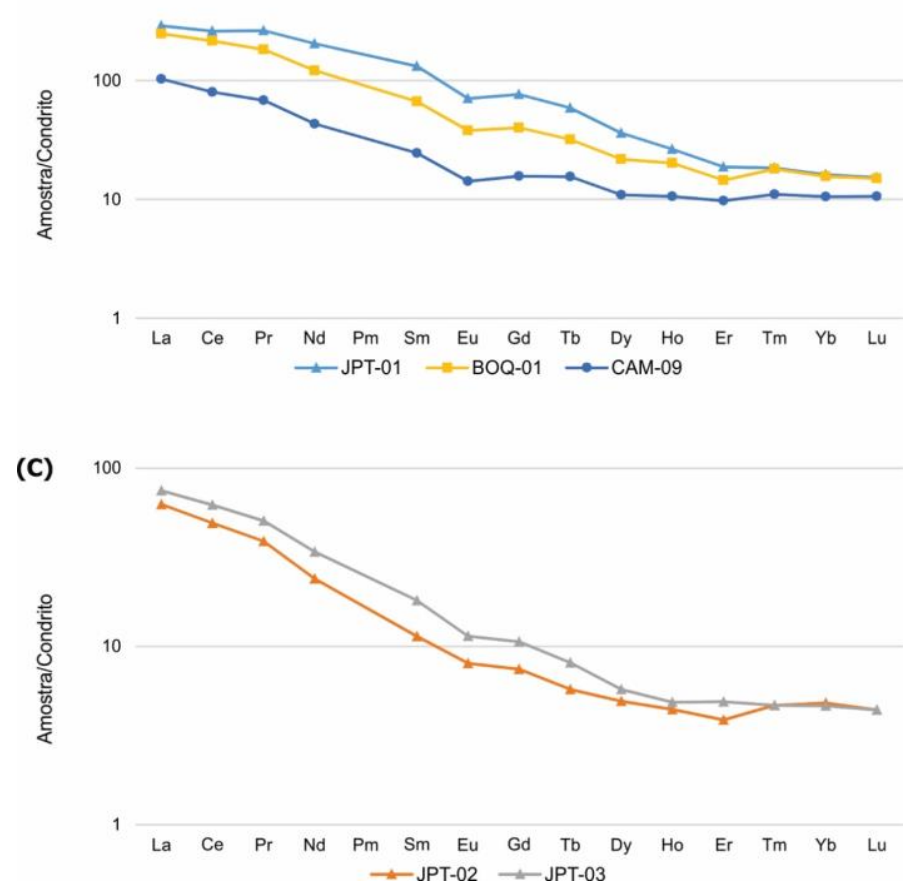

Figura 9 - (A) Diagrama de elementos terras raras normalizado pelo condrito (Nakamura, 1974) para as amostras selecionadas; (B) Padrões para as amostras JPT-01, BOQ-01 e CAM-09; (C) Assinatura das amostras JPT-02 e JPT-03. 


\section{DISCUSSÃO E CONCLUSÕES}

Os resultados obtidos com o estudo geoquímico mostram uma correlação com o petrográfico. O alto grau de alteração com presença de grande proporção de argilominerais de dissolução em feldspatos observado em lâmina petrográfica é também corroborado na geoquímica, que nos elementos maiores exibe índices de alteração CIA e PIA elevados; anomalias positivas de $\mathrm{K}_{2} \mathrm{O}$ relativas a média da crosta continental (Taylor \& McLennan, 1995) ocasionadas pelo crescimento supergênico de potássio, relativo a lixiviação de outros elementos químicos a exemplo do cálcio e magnésio , correlação positiva entre $\mathrm{K}_{2} \mathrm{O}$ e $\mathrm{Na}_{2} \mathrm{O}$ e depleção da $\mathrm{Ca}_{2} \mathrm{O}$. Para os elementos traço observa-se uma depleção de $\mathrm{Sr}$, associada à perda de $\mathrm{Ca}_{2} \mathrm{O}$ devido a dissolução e substituição de plagioclásio e anomalias positivas de $\mathrm{Rb}$ e $\mathrm{Ba}$, que estão geoquimicamente associados com o aumento da proporção de $\mathrm{Na}_{2} \mathrm{O}$. Além disso, todas as amostras apresentam uma razão $\mathrm{K}_{2} \mathrm{O} / \mathrm{Na}_{2} \mathrm{O}$ superior a 1 enquanto que a razão $\mathrm{K}_{2} \mathrm{O} / \mathrm{Al}_{2} \mathrm{O}_{3}$ exibida é inferior a 1, afirmando a ação do intemperismo e crescimento supergênico de $\mathrm{Al}_{2} \mathrm{O}_{3}$ relativo a $\mathrm{K}_{2} \mathrm{O}$ e $\mathrm{Na}_{2} \mathrm{O}$.

$\mathrm{O}$ gráfico multielementar para elementos traço dessas amostras (Figura 7) pode ser separado quando a semelhança em três grupos: um padrão similar para as amostras JPT-02 e JPT-03, que foram extraídas de uma mesma fácies que exibe paleocorrente principal para sudeste, um padrão para as amostras JPT-01 e BOQ-01, que apresentam mesma direção dominante de paleocorrente, sudoeste, e um terceiro padrão para a amostra CAM-09 do afloramento Morro de Camaragibe, que também apresenta paleocorrente para sudoeste. O spidergrama das amostras permite a divisão dessas amostras em dois grupos quanto a proporção de ETRp e pelo padrão de anomalia de Eu. O primeiro grupo inclui as amostras JPT-01, BOQ-01 e CAM-09 e apresenta concentração de ETRp superior a 10 com relação ao condrito, além de uma anomalia de Eu mais acentuada relativa às amostras do outro grupo que é composto pelas amostras JPT-02 e JPT-03, que também diferenciam-se do primeiro grupo por apresentar uma concentração de ETRp entre 1 e 10 relativa ao condrito.

Considerando a configuração do sistema fluvio-deltaico-turbidítico em que esses sedimentos foram depositados, e levando em consideração a distância do sítio deposicional relativo à área fonte e também quanto à direção de suas paleocorrentes, podemos inferir que as amostras com direção de paleocorrente SW apresentam áreas fontes distintas daquelas amostras com direção principal de paleocorrente SE. Além disso, para as amostras com direção de paleocorrente SW, é notável uma maior semelhança entre as amostras JPT-01 e BOQ-01, com relação à amostra CAM-09. Isso é explicado pela distância da deposição. Enquanto que as duas primeiras amostras fazem parte das porções dominantemente fluvio-deltaica do sistema e estão mais próximas da área fonte, a terceira encontra-se sedimentada nos depósitos de franja do sistema turbidítico. Essa diferença no transporte pode ter sido o fator responsável pela diferença na composição das amostras. Enquanto que as amostras extraídas de fácies com paleocorrente SE (JPT-02 e JPT-03) a principal área fonte estaria situada a NE (borda falhada da bacia), as amostras de fácies que apresentam paleocorrente para SW (JPT01, BOQ-01 e CAM-09) teriam sua área fonte localizada na porção axial do sistema (NW). Além disso, dados de geocronologia U-Pb em zircão detrítico nesses mesmos afloramentos publicados por Almeida et al. (em preparação) confirmam a presença de diferentes áreas fontes para esses grupos de amostras.

\section{AGRADECIMENTOS}

As autoras agradecem o suporte financeiro do Conselho Nacional de Desenvolvimento Científico e Tecnológico (CNPq) e à Fundação de Apoio à Pesquisa e à Inovação Tecnológica do Estado de Sergipe (FAPITEC), processos números 308059/2014-0 (CNPq-PQ) e 019.203.02538/2009-7 (PRONEX/FAPITEC/CNPq) e à Petrobras (UO-SEAL/EXP/SE) pelo suporte nos trabalhos de campo e nas descrições petrográficas. Agradecem também aos avaliadores anônimos da revista cujas sugestões e críticas construtivas aperfeiçoaram o trabalho apresentado. 


\section{REFERÊNCIAS}

ALMEIDA, G.M. Estudo de proveniência da sedimentação aptiana aflorante na porção Norte da Sub-Bacia de Alagoas. São Cristóvão, 2016, 95 p. Dissertação (Mestrado em Geociências), Universidade Federal de Sergipe.

ALMEIDA, G.M., MENEZES, M.R.F., ROSA, M.L.S. U-Pb dating of detrital zircon and its implications for provenance of the sediments of the emerged Aptian rift section of Basin of Sergipe-Alagoas, NE Brazil (em preparação).

ARIENTI, L.M. Análise estratigráfica, estudos de fluxos gravitacionais e geometria dos depósitos "rift" da Formação Maceió e Formação Poção, Bacia de Alagoas. Porto Alegre, 1996, 398 p. Tese (Doutorado em Geociências), Universidade do Rio Grande do Sul.

ARIENTI, L.M. Depósitos de fluxos gravitacionais da Formação Maceió - Bacia de Alagoas, NE do Brasil. Boletim de Geociências da Petrobras, v. 14, n. 2, p. 357-385, 2006.

BATHIA, M.R., CROOK, K.A.W. Trace element characteristics of greywackes and tectonic discrimination of sedimentary basins. Contributions to Mineralogy and Petrology, v. 92, n. 2, p. 181-193, 1986.

BAULUZ, B., MAYAYO, M.J., FERNANDEZ-NIETO, C., LOPEZ, J.M.G. Geochemistry of Precambrian and Paleozoic siliciclastic rocks from the Iberian Range (NE Spain): Implications for source-area weathering, sorting, provenance, and tectonic setting. Chemical Geology, v. 168, n. 1, p. 135$150,2000$.

CAMPOS NETO, O.P.A., SOUZA-LIMA, W., CRUZ, F.E.G. Bacia de Sergipe-Alagoas. Boletim de Geociências Petrobras, v. 15, n. 2, p. 405-415, 2007.

CAWOOD, P.A. \& NEMCHIN, A.A. Provenance record of a rift basin: $\mathrm{U} / \mathrm{Pb}$ ages of detrital zircons from the Perth Basin, Western Australia. Sedimentary Geology, v. 134, n. 3-4, p. 209-234, 2000.

CARVALHO, M.A., MENDONÇA FILHO, J.G., MENEZES, T.R. Palynofacies and sequence stratigraphy of the AptianAlbian of the Sergipe Basin, Brazil. Sedimentary Geology, v. 192 , p. $57-74$.

CRUZ L.R. Caracterização Tectono-Estratigráfica da Sequência Transicional na Sub-Bacia de Sergipe. Natal, 2008, 169 p. Tese (Doutorado em Geodinâmica e Geofísica), Universidade Federal do Rio Grande do Norte.

DICKINSON, W.R. Interpreting provenance relations from detrital modes of sandstones. In: ZUFFA, G.G. (Ed.) Provenance of Arenites. Dordrecht, Germany, D. Reidel Publishing Company, p. 333-361, 1985.

DICKINSON, W.R. \& SUZEK, C.A. Plate tectonics and sandstone composition. AAPG Bulletin. v. 63, p. 2164-2182, 1979.

FEDO, C.M., NESBITT, W.H., YOUNG, G.M. Unraveling the effects of potassium metasomatism in sedimentary rocks and paleosols, with implications for paleoweathering conditions and provenance. Geology, v. 23, n. 10, p. 921-924, 1995.

FEDO, C.M., SIRCOMBE, K.N., RAINBIRD, R.H. Detrital zircon analysis of the sedimentary record. In: HANCHAR, J.M., HOSKIN, P.W.O. (Eds.) Reviews in Mineralogy \& Geochemistry. Mineralogical Society of America, v. 53, p. 277-303, 2003.

FOLK R.L. Petrology of Sedimentary Rocks. Hemphill Publishing Company, Austin, Texas, 184p, 1968.

FORNELLI, A., MICHELETTI, F., LANGONE, A., PERRONE, V. First U-Pb detrital zircon ages from Numidian sandstones in Southern Apennines (Italy): Evidences of African provenance. Sedimentary Geology, v. 320, p. 19-29, 2015.

HARTT, C.F. Geology and physical geography of Brazil. Fields. Osgood \& Co., Boston, 620 p., 1870.

JANOUŠEK, V., FARROW, C.M., ERBAN, V. Interpretation of Whole-Rock Geochemical Data in Igneous Geochemistry:
Introducing Geochemical Data Toolkit (GCDKit). Journal of Petrology, v. 47, p. 1255-1259, 2006.

JORGE, R.C.G.S., FERNANDES, P., RODRIGUES, B., PEREIRA, Z., OLIVEIRA, J.T. Geochemistry and provenance of the Carboniferous Baixo Alentejo Flysch Group, South Portuguese Zone. Sedimentary Geology, v. 284-285, p. 133-148, 2013.

LINK, P.K., FANNING, C.M., BERANEK, L.P. Reliability and longitudinal change of detrital-zircon age spectra in the Snake River system, Idaho and Wyoming: An example of reproducing the bumpy barcode. Sedimentary Geology, v. 182, p. 102-142, 2005.

LIRA A.R.A. 2004. Caracterização em multiescala de análogos de reservatórios da Formação Maceió (Aptiano da Bacia de Alagoas), nas regiões de Japaratinga e Morro de Camaragibe - AL. Recife, 2004, 184 p. Tese (Doutorado em Geociências) Centro de Tecnologia e Geociências, Universidade Federal de Pernambuco.

MANGE, M.A. \& MORTON, A.C. Geochemistry of heavy minerals. In: MANGE M.A. \& WRIGHT D.T. (EDS.) Developments in Sedimentology, v. 58, p. 345-391, 2007.

MATOS, R.M.D. Tectonic and stratigraphic development of the West African and eastern Brazilian Margins: insights from quantitative basin modelling. In: CAMERON, N. R., BATE, R. H. \& CLURE, V. S. (EDS.), The Oil and Gas Habitats of the South Atlantic, Geological Society, London, Special Publications v. 153, p. 55-73, 1999.

MCLENNAN, S.M., TAYLOR, S.R., MCCULLOCH, M.T., MAYNARD, J.B. Geochemical and $\mathrm{Nd}-\mathrm{Sr}$ Isotopic Composition of Deep-Sea Turbidites - Crustal Evolution and Plate Tectonic Associations. Geochimica et Cosmochimica Acta, v. 54, n. 7, p. 2015-2050, 1990.

MORTON, A.C. Geochemical studies of detrital heavy minerals and their application to provenance research. In: MORTON A.C., TODD S.P, HAUGHTON P.D.W. (EDS.) Developments in Sedimentary Provenance Studies. Geological Society of London, Special Publications, v. 57, p. 31-45, 1991.

MORTON, A.C. \& HALLSWORTH, C.R. Identifying provenience-specific features of detrital heavy mineral assemblages in sandstones. Sedimentary Geology, v. 90, p. 241-256, 1994

MORTON, A.C., CLAOUÉ-LONG, J.C., BERGE, C. SHRIMP constraints on sediment provenance transport history in the Mesozoic Statfjord Formation, North Sea. Journal of the Geological Society of London, v. 153, p. 915-929, 1996.

NASCIMENTO M.C. \& LIMA FILHO M. Fácies da Formação Maceió (Aptiano-Albiano) na porção norte da Bacia Alagoas. Estudos Geológicos, v. 13, p. 217-233, 2005.

NESBITT, H.W. \& YOUNG, G.M. Early Proterozoic climates and plate motions inferred from major elements chemistry of lutites. Nature, v. 299, p. 715-717, 1982.

Continuing Education Course Note Series v. 39, 61 p., 1999.

NAKAMURA, N. Determination of REE, Ba, Fe, Mg, Na, and $\mathrm{K}$ in carbonaceous and ordinary chondrites. Geochimica et Cosmochimica Acta, v. 38, p. 757-775, 1974.

ROBACK, R.C. \& WALKER, N.W. Provenance, detrital zircon $\mathrm{U}-\mathrm{Pb}$ geochronomery, and tectonic significance of Permian to Lower Triassic sandstone in southeasthern Quesnellia, British Columbia and Washington. Geological Society of America Bulletin, v. 107, p. 665675,1995

ROLLINSON, H.R. Using Geochemical Data: Evaluation, Presentation, Interpretation. Longman Geochemistry Series, Routledge, New York, 384 p. 1993.

SCHALLER, H. Revisão estratigráfica da Bacia de Sergipe/Alagoas. Boletim Técnico Petrobrás, v. 12, n. 1, p.21-86, 1969. 
SILVA FILHO, A.F., GOMES, H.A., OSAKO, L.S., GUIMARÃES, I.P., BRASIL, E.A., LIMA, D.R., COCENTINO, L., VILLAVERDE, V.G.R., VASCONCELOS, V.L. Geologia da Folha de GaranhunsSC.24-X-B-VI, escala 1:100.000: nota explicativa. Programa Geologia do Brasil: Levantamentos Geológicos Básicos. Pernambuco/Alagoas, UFPE/CPRM. 2008.

SILVA FILHO, A.F., GUIMARÃES, I.P., VAN SCHMUS, W.R., ARMSTRONG, R.A., SILVA, J.M.R, OSAKO, L.S., CONCENTINO, L.M. SHRIMP U-Pb zircon geochronology and $\mathrm{Nd}$ signatures of supracrustal sequences and orthogneisses constrain the Neoproterozoic evolution of the Pernambuco-Alagoas domain, southern part of Borborema Province, NE Brazil. International Journal of Earth Sciences. v. 103, n. 8, p. 2155-2190. 2014.

SIQUEIRA D.V. Arquitetura deposicional 2D da Formação Maceió, nos afloramentos de Japaratinga, Barreiras do Boqueirão e Morro de Camaragibe - Bacia de Alagoas. Recife, 2002, 123 p. Dissertação (Mestrado em Geociências), Centro de Tecnologia e Geociências, Universidade Federal de Pernambuco.

SIRCOMBE, K.N. Tracing provenance through the isotope ages of littoral and sedimentary detrital zircon, eastern Australia. Sedimentary Geology, v. 124, p. 47-67, 1999.
SOUZA-LIMA, W., ANDRADE, E.J., BENGSTON, P., GALM, P.C. A Bacia de Sergipe-Alagoas: evolução geológica, estratigrafia e conteúdo fóssil. Fundação Paleontológica Phoenix, Edição Especial, 31 p., 2002.

TAYLOR, S.R. \& MCLENNAN, S.M. The geochemical evolution of the continental crust. Reviews in Geophysics, v. 33, p. 241-265, 1995.

ZHAO, B., WANG, C., WANG, X., FENG, Z. Late Cretaceous (Campanian) provenance change in the Songliao Basin, NE China: Evidence from detrital zircon $\mathrm{U}-\mathrm{Pb}$ ages from the Yaojia and Nenjiang Formations. Palaeogeography, Palaeoclimatology, Palaeoecology, v. 385, p. 83-94, 2013.

ZUFFA G.G. Optical analise of arenites: influence of methodology in compositional results. In: ZUFFA G.G. (Ed.) Provenance of Arenites. Dordrecht, Germany, D. Reidel Publishing Company, p. 165-189, 1985.

Submetido em 20 de outubro de 2016 Aceito em 18 de janeiro de 2017 